REGULAR ARTICLE

\title{
INFLUENCE OF BRINE COMPOSITION AND CONCENTRATION ON MICROBIAL GROWTH DURING WHOLE COMMON BEAN (Phaseolus vulgaris L) FERMENTATION USING Lactobacillus plantarum BFE 5092
}

\author{
Vivian C. Kitum ${ }^{1}$, Peter K. Kinyanjui ${ }^{* 1}$, Julius M. Mathaara ${ }^{l}$ and Daniel N. Sila ${ }^{1}$ \\ Address (es): Dr Peter Kinyanjui, \\ ${ }^{1}$ Jomo Kenyatta University of Agriculture and Technology, Faculty of Agriculture, Department of Food Science, P.O Box 62000-00200, Nairobi, Kenya, +254-67- \\ 52711.
}

*Corresponding author: pkahenya@gmail.com

\section{ABSTRACT}

Fermentation technology improves the flavour and shelf-life of foods while lowering antinutrient levels. Common bean, though a highly nutritious food, contains high levels of anti-nutrients. Fermentation can be exploited to lower antinutrients in common bean. Though significant strides have been made in bean milk and flour fermentation, common bean is majorly consumed as whole grain. This study, therefore, was aimed at developing a fermentation protocol for the whole common bean. Lactobacillus plantarum BFE 5092 was used as starter culture for fermentation. Salt and salt-sugar at $1 \%, 2 \%$ and $3 \%$ solute concentrations were used as brine. The effect of starter culture, solute composition and concentration on the growth of lactic acid bacteria (LAB) was monitored. $\mathrm{pH}$ and microbial safety were also monitored during the fermentation process. Inoculation with Lactobacillus plantarum BFE 5092 caused a significant increase $(\mathrm{P}<0.05)$ of LAB counts in salt brine systems compared to spontaneous fermentation but no significant difference $(\mathrm{P}>0.05)$ in salt-sugar brine systems. The $\mathrm{pH}$ of salt-sugar brine systems was significantly $(\mathrm{P}<0.05)$ lowered during the fermentation process from 6.07 to $\leq 3.75$. This inhibited enterobacteria growth while promoting the growth of yeast. In salt brine systems, the $\mathrm{pH}$ was $\geq 4.8$ favoring enterobacterial growth while inhibiting yeast growth. Solute concentration had no significant effect $(\mathrm{P}>0.05)$ on the growth of LAB, $\mathrm{pH}$ and microbial safety during fermentation. The study established that use of salt-sugar brine system was effective in promoting the growth of LAB and microbial safety during whole common bean fermentation.

Keywords: Brine, lactic acid bacteria, inoculation, spontaneous fermentation, Lactobacillus plantarum BFE 5092

\section{INTRODUCTION}

Common bean (Phaseolus vulgaris L) is a leguminous plant cultivated worldwide (Berrios et al., 2010). It constitutes an important part of the East and central African countries' diet (Granito \& Alvarez, 2006). In Kenya, common beans are commonly consumed as 'githeri' a mixture of the beans and maize. It can also be stewed as an accompaniment for various starches. Common bean is a renowned nutritionally rich pulse. It contains practically almost all nutrients including; proteins, complex carbohydrates, vitamin B, folic acid (Mcphee et al., 2002), dietary fibre and minerals including iron, copper, zinc, phosphorus, potassium, magnesium and calcium (Legesse et al., 2015). However, it's consumption is limited because of flatulence and abdominal discomfort (Granito \& Alvarez, 2006) related to its consumption. This is contributed by the high raffinose family oligosaccharide (RFOs) and anti-nutrient composition in the common bean (Agarwal, 2016).

Fermentation is one of the oldest technologies used at household and commercial level to produce a variety of foods (Onwurafor et al., 2014). Microbial activity during fermentation results in biochemical modification of the food (Issofou, 2010). This contributes to increased shelf-life, improved flavours as well as lowered anti-nutrient composition in the fermented product.The technology has also been proven to lower the RFOs and other anti-nutritional components in legumes and their products (Assohoun et al., 2013; Osman \& Gassem, 2013). Use of cover brines during batch fermentation of vegetable and plant material is common. The solute in cover brine plays a great role in drawing out juices from the plant material for the fermentative microorganisms to utilize. Solute concentration and composition in the brine is key in the fermentation process (Reina et al., 2015). $\mathrm{NaCl}$ in brines promotes the growth of lactic acid bacteria (Pundir \& Jain, 2010; Reina et al., 2015) whereas addition of sugar to cover brines provides additional carbon source to promote the growth of the fermentative microorganisms.

Lactic acid bacteria (LAB) are the most common fermentative microorganisms in plant material fermentation. These are a diverse group of non-motile, catalase negative, Gram-positive rods or cocci. These bacteria utilize a wide variety of carbohydrates as carbon source and produce lactic acid as a major or sole metabolic end-product (El-din, 2010). The produced acid lowers $\mathrm{pH}$ of the fermentation system consequently restricting the proliferation of Gram-negative and other competing microorganisms. Lactobacillus plantarum is an important $\mathrm{LAB}$ in the fermentation of many plant products (Maina et al., 2008). Lactobacillus plantarum strains are known to produce several bacteriocins which can act as antimicrobial agents against some Gram-positive bacteria (Anderssen et al., 1998; Cho et al, 2010). Lactobacillus plantarum strains have the added advantage of having probiotic effects as they are tolerant to gastric and bile acid in the human gut (Ammor \& Mayo, 2007; Xiong et al., 2012). Lactobacillus plantarum BFE 5092 strain was isolated from Kule naoto a traditionally fermented milk product from the Maasai community of Kenya (Maina et al., 2004). It has a genome size of $3,285094 \mathrm{bp}$ with 433 of its genes involved in sugar metabolism (Oguntoyinbo et al., 2016). Maina et al. (2008) showed the ability of Lactobacillus plantarum BFE 5092 to survive through the gastrointestinal tract in an in-vitro model hence its probiotic potential. It also has been shown to possess genes for production of plantaricins EF and JK (Cho et al., 2010) thus the potential to inhibit Gram-positive pathogens. Studies on the application of Lactobacillus plantarum BFE 5092 as a starter culture in the fermentation of indigenous African leafy vegetables have been carried out (Wafula et al., 2015).

Common bean fermentations on milled bean flours and extracted milk has been documented. Onwurafor et al., 2014 and Tope, 2014 fermented mung bean flour and ground lima bean. They reported improved nutritional and lowered antinutritional composition in these flours. Saraswathy \& Sadasivam, 2010 determined the enzymatic effect of $\alpha$-galactosidase on oligosaccharides in extracted soy milk. In Kenya, common bean is majorly consumed as whole grain. It is therefore paramount that a technology that will increase the utilization of common bean in its conventional way be developed. This research aimed at developing a protocol for the fermentation of whole common beans.

\section{MATERIALS AND METHODS}

\section{Materials}

Red haricot beans were acquired from the National Cereals and Produce Board Nairobi Kenya. The starter culture used, Lactobacillus plantarum BFE 5092 was obtained from the Food Science Department at Jomo Kenyatta University of Agriculture and Technology. The media used for culturing and enumeration of bacteria, yeast and moulds were from Himedia, Mumbai India. The table salt $(\mathrm{NaCl})$ and sugar used in this study were purchased locally.

\section{Methods}

Fermentation protocol

Preparation of beans

The beans were hand sorted to remove foreign materials and any defective grain. They were then washed under running tap water and soaked for $12 \mathrm{~h}$ in distilled 
water at a ratio of $1: 5 \mathrm{w} / \mathrm{v}$. The soaking water was then drained, and the beans were rinsed. The beans were then boiled for $60 \mathrm{~min}$ on an LPG stove. The boiling water was then drained and the beans allowed to cool to about $60^{\circ} \mathrm{C}$. Two hundred Grams of the cooked beans were then weighed out using a sterilized scoop spoon into zip-lock bags and frozen for $72 \mathrm{~h}$ at $-4{ }^{\circ} \mathrm{C}$ awaiting fermentation.

\section{Preparation of fermentation solution}

Fermentation brines were prepared by weighing 6,12 and 18 gms of salt, and into $1000 \mathrm{ml}$ fermentation bottles, in duplicate. Then $600 \mathrm{ml}$ of distilled water was added into the fermentation bottles. The bottles were shaken to dissolve the salt. This resulted in $1 \%, 2 \%$ and $3 \%$ concentrated salt brine. The same procedure was used to weigh salt and sugar at a ratio of $1: 1$. This resulted in $1 \%$, $2 \%$ and $3 \%$ concentrated salt-sugar brine. The brines were then sterilized in an autoclave at $121{ }^{\circ} \mathrm{C}$ for $15 \mathrm{~min}$. They were allowed to cool to room temperature before use in fermentation.

\section{Starter culture preparation}

One hundred microliters of cryopreserved Lactobacillus plantarum BFE 5092 starter culture were transferred into $9 \mathrm{ml}$ De Mann, Ragosa and Sharpe (MRS) broth. This was then incubated at $30^{\circ} \mathrm{C}$ for $24 \mathrm{~h}$. The overnight cultures were then vortexed and a loop-full streaked on De Mann, Ragosa and Sharpe (MRS ) agar plate. It was then incubated for another $24 \mathrm{~h}$ at $30^{\circ} \mathrm{C}$ to check for purity. A pure colony was then transferred into MRS broth and incubated for $24 \mathrm{~h}$ at $30^{\circ}$ C. One millilitre of the cells were then transferred into $1.5 \mathrm{ml}$ Eppendorf tube and vortexed at 13,000 rotations per minute (rpm) for $5 \mathrm{~min}$. The supernatant was discarded and the pellet dissolved in $600 \mu 1$ sterile ringer solution. This was used as a starter culture in one set of the fermentation bottles accounting for $10^{6}$ colony forming units per mililiter (cfu/ml).

\section{Fermentation}

Fermentation was performed in two sets, one inoculated with starter culture strain Lactobacillus plantarum BFE 5092 (experimental set) and the other without starter culture (control set). Each set had six batches made up of sterile $1 \%$ salt, $2 \%$, salt, $3 \%$ salt, $1 \%$ salt-sugar, $2 \%$ salt-sugar and $3 \%$ salt-sugar brine systems.

The frozen beans were thawed in a cold room $\left(15^{\circ} \mathrm{C}\right)$ for $24 \mathrm{~h}$. Approximately $200 \mathrm{~g}$ of beans were transferred into each fermentation bottle above. This resulted in fermentation ratio of 1:3 w/v. The overnight starter culture was vortexed and transferred into the experimental set. The beans were left to ferment at $25^{\circ} \mathrm{C}$ for $120 \mathrm{~h}$. Approximately $5 \mathrm{ml}$ of brine samples were collected daily at $0 \mathrm{~h}, 24 \mathrm{~h}, 48 \mathrm{~h}, 72 \mathrm{~h}$ and $120 \mathrm{~h}$ for the $\mathrm{pH}$ determination and microbial enumeration.

\section{pH determination}

The $\mathrm{pH}$ was used to study fermentation dynamics at $0 \mathrm{~h}, 24 \mathrm{~h}, 48 \mathrm{~h}, 72 \mathrm{~h}, 96 \mathrm{~h}$ and $120 \mathrm{~h}$ using a pH meter (HI 2211, Hanna Instruments, Japan).

\section{Microbial enumeration during fermentation}

Five millilitres of the fermentation solution was transferred into a sterile test tube. This was vortexed to achieve a homogenous mix then serially diluted in test tubes containing sterile quarter-strength ringer's solution. These preparations were thoroughly mixed by vortexing and $10 \mu l$ of the aliquots from different dilutions spread-plated in duplicates on Petri dishes. These Petri dishes contained; MRS agar for LAB enumeration, Violet Red Bile Glucose Agar (VRBGA) for enterobacteria enumeration, Plate Count Agar (PCA) for total aerobic bacteria count and Potato Dextrose Agar (PDA) supplemented with 40\% tartaric acid for yeast and mould enumeration. The Petri dishes were then incubated at respective temperatures; MRS at $30^{\circ} \mathrm{C}$ VRBGA and PCA at $37^{\circ} \mathrm{C}$ and PDA at $25^{\circ} \mathrm{C}$. Counting of colony forming units was done on a daily basis for $120 \mathrm{~h}$. This was to monitor microbial growth during fermentation of whole common beans. The cfu/ml of the samples was calculated using the following formula:

$$
\text { Colony forming unit }(\mathrm{cfu} / \mathrm{ml})=\frac{\text { Number of colonies }}{\text { Volume of inoculum }} \mathrm{X} \text { Dilution factor }
$$

\section{Data Analysis}

The means of colony counts from the experiments were subjected to analysis of variance and t-test based on the variables. Posthoc analysis was done using LSD to determine the significant difference. $R_{\times} 64$ 3.3.1. statistical software was used.

\section{RESULTS AND DISCUSSION}

\section{Effect of brine composition and concentration on the growth of LAB}

The changes that occurred in LAB growth during fermentation of common beans in salt brine system and salt-sugar brine systems are presented in Figures 1 and 2 respectively.

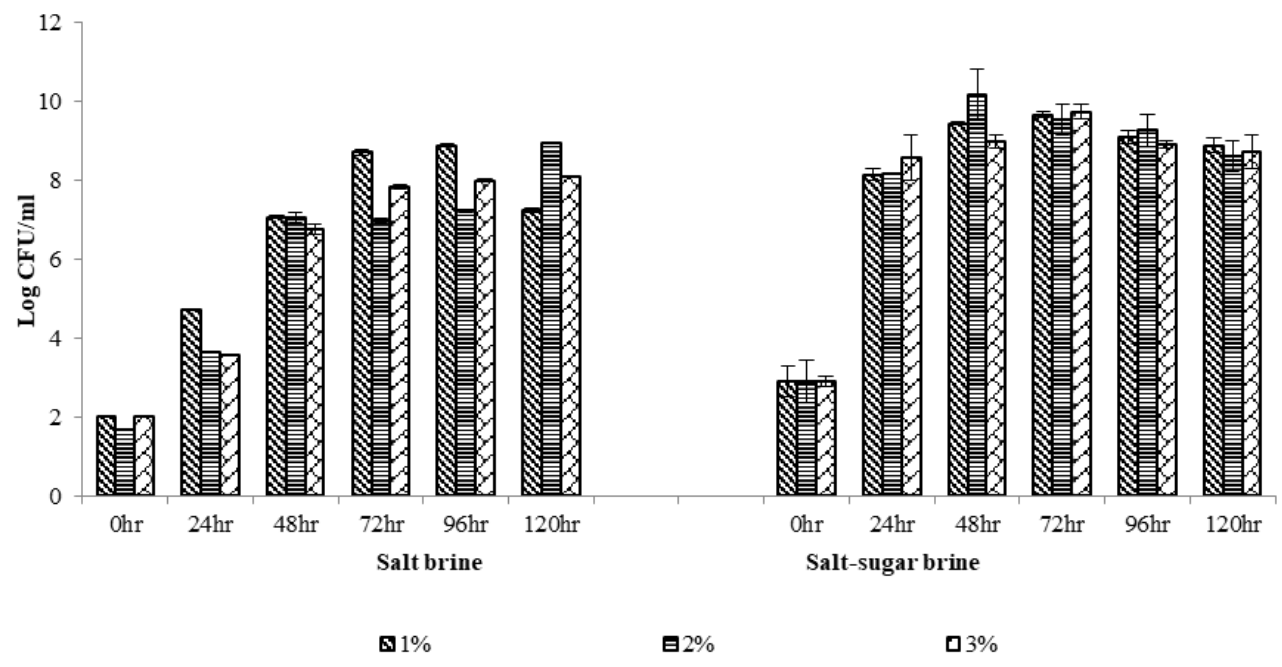

Figure1 The mean lactic acid bacteria counts \pm SEM from duplicate spontaneous fermention of common beans in $1 \%, 2 \% \& 3 \%$ salt and salt-sugar brine systems

During spontaneous fermentation, $\mathrm{LAB}$ count at $0 \mathrm{~h}$ was $<10^{3} \mathrm{cfu} / \mathrm{ml}$ in both salt and salt-sugar brine systems (Fig.1). This is an indication that LAB proliferated during thawing of the cooked beans. Their counts increased gradually with fermentation in salt brine systems reaching $>10^{7} \mathrm{cfu} / \mathrm{ml}$ after $48 \mathrm{~h}$ of fermentation. The maximum growth of about $10^{8} \mathrm{cfu} / \mathrm{ml}$ was observed between $72-96 \mathrm{~h}$ in $1 \%$ salt brine system and after $120 \mathrm{~h}$ in $2 \%$ and $3 \%$ salt brine systems. When salt-sugar brine systems were used, a significant increase
$(\mathrm{P}<0.05)$ of $\mathrm{LAB}$ was observed after $24 \mathrm{~h}$ from $10^{3}$ to $10^{8} \mathrm{cfu} / \mathrm{ml}$ (Fig.1) Maximum growth of between $10^{9}$ and $10^{10} \mathrm{cfu} / \mathrm{ml}$ occurred between $48 \mathrm{~h}$ and 72 $\mathrm{h}$ in spontaneous fermentation.The increase in LAB counts during spontaneous fermentation indicates the ability autochthonous LAB to utilize substrates in common bean (Chelule et al.,2010). It could also be attributed to the presence of salt in cover brine which favours the growth of LAB (Pundir \& Jain, 2010; Reina et al., 2015) during fermentation. 


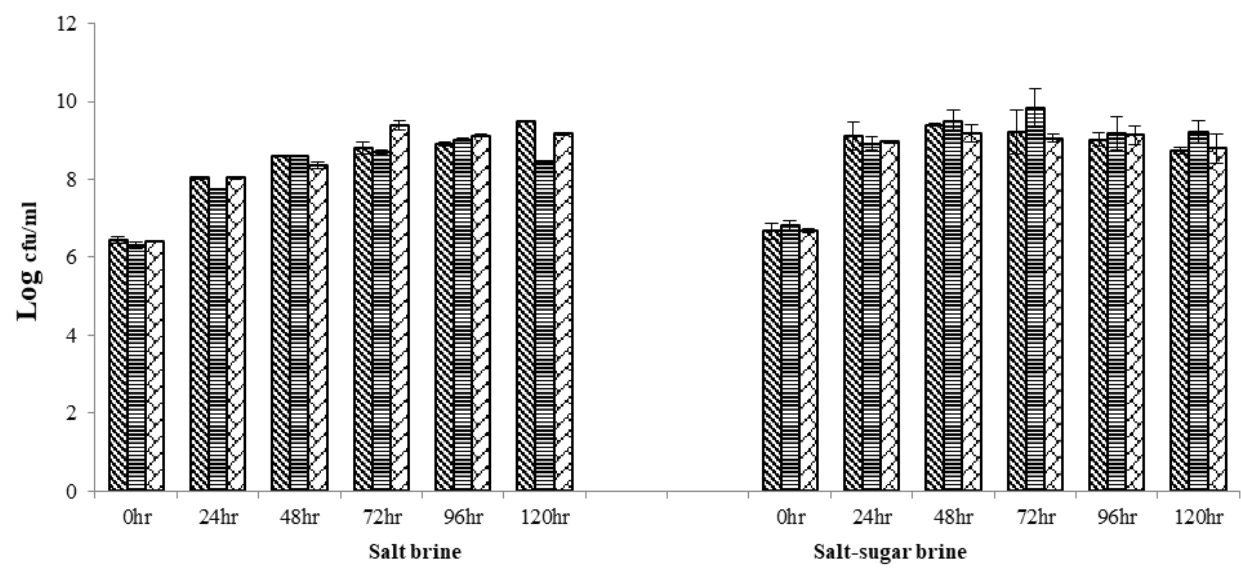
ه $1 \%$
日 $2 \%$
$\square 3 \%$

Figure 2 The mean lactic acid bacteria counts \pm SEM from duplicate common bean fermentations inoculated with Lactobacillus plantarum BFE 5092 in 1\%,2\% \& 3\% salt and salt-sugar brine systems

When the batches were inoculated with Lactobacillus plantarum BFE 5092, LAB counts increased significantly $(\mathrm{P}<0.05)$ in both salt and salt-sugar brine systems (Fig.2). They increased from $10^{6}$ to $10^{8} \mathrm{cfu} / \mathrm{ml}$ between $24 \mathrm{~h}$ and $48 \mathrm{~h}$ in salt brine system, whereas salt-sugar brine systems led to an increase from $10^{6}$ to $10^{9} \mathrm{cfu} / \mathrm{ml}$ was observed after $24 \mathrm{~h}$ (Fig.2) of fermentation. The counts remained at this high level until after $120 \mathrm{~h}$ of fermentation. Higher Lactobacillus plantarum counts in salt-sugar brine systems compared to that in salt brine systems (Fig.2) is attributed to the readily available fermentable sugars for LAB metabolism. LAB counts were lower in the spontaneously fermented batches compared to those inoculated with Lactobacillus plantarum BFE 5092. These findings are in agreement with Sanchez et al. (2001) who reported that the use of Lactobacillus starter cultures led to higher population of viable Lactobacillus in inoculated samples compared to the spontaneously fermented ones.

A slow decline of $\mathrm{LAB}$ counts in both the inoculated and spontaneously fermented batches was observed after $96 \mathrm{~h}$ fermentation in salt-sugar brine systems but not in salt brine system. This is attributable to the high acid concentration (Pundir \& Jain, 2010) in the fermentation system as indicated by low $\mathrm{pH}$ in the salt-sugar brine systems (Fig.3).The growth of LAB in 1\%, 2\% and 3\% salt concentration and salt and sugar concentration was not significantly different.

\section{Changes in $\mathrm{pH}$ during common bean fermentation}

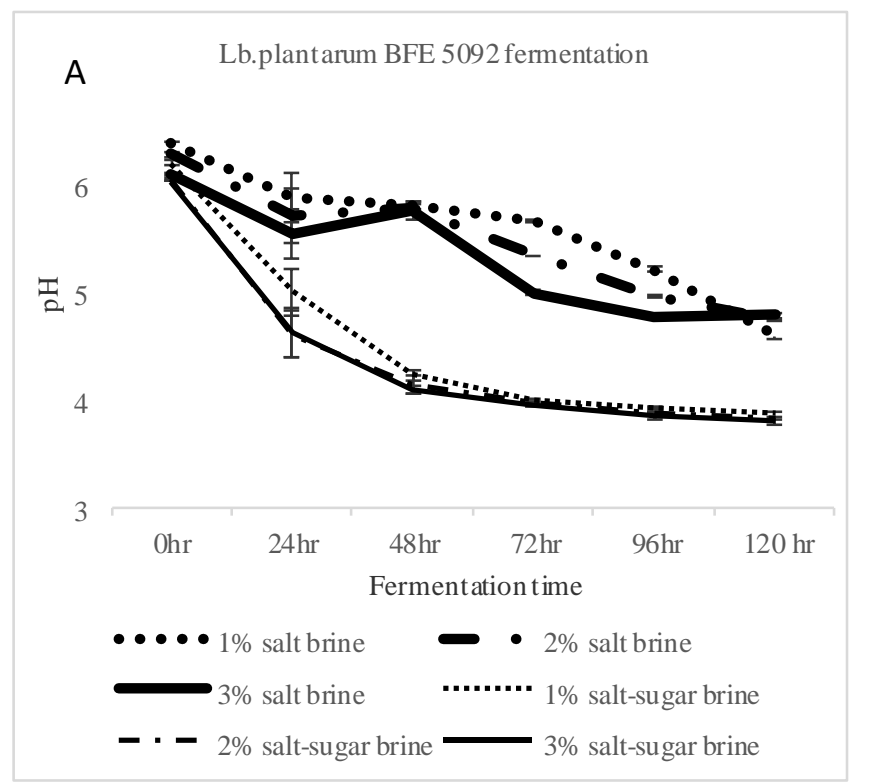

Lactic acid bacteria produce acid during fermentation lowering the $\mathrm{pH}$ of the fermentation system. During fermentation of common beans in salt brine systems, the $\mathrm{pH}$ declined significantly from 6 to 5 after $24 \mathrm{~h}$ of fermentation (Fig.3) attributable to acid production. The $\mathrm{pH}$ then rose after $48 \mathrm{~h}$ of fermentation in both inoculated and spontaneously fermented batches before declining again with further fermentation. This phenomenon was also observed by Assohoun et al. (2013), Ojokoh et al. (2013) and Granito \& Alvarez, (2006) during fermentation of Doklu, cowpea and black bean respectively. Importantly, batches inoculated with Lactobacillus plantarum BFE 5092 were able to lower the $\mathrm{pH}$ below 4.8 at the end of fermentation. This is an indication that LAB in the starter culture were able to stabilize and grow during fermentation. $\mathrm{pH}$ remained above 5 at the end of spontaneous fermentation with salt brine. Higher LAB counts in inoculated salt brine batches (Fig.2) resulted in lower $\mathrm{pH}$ and vice versa.

When salt-sugar brine was used, the $\mathrm{pH}$ declined significantly $(\mathrm{P}<0.05)$ after 24 $\mathrm{h}$ of fermentation, from $\geq 6$ to $\leq 4.8$. This sharp decrease could be attributed to the increased metabolic activity of the LAB due to the readily available carbon source from sugar. The $\mathrm{pH}$ decreased to $\leq 4$ within $72 \mathrm{~h}$ of fermentation which is in agreement with the findings of Onwurafor $\boldsymbol{e t}$ al. (2014). He established a decline of $\mathrm{pH}$ from 6.24 to 3.68 and 3.87 after 72 hours of spontaneous and back slopping fermentation of mung bean respectively. At the end of fermentation, the $\mathrm{pH}$ was below 3.8 in both innoculated and spontaneously fermented batches.

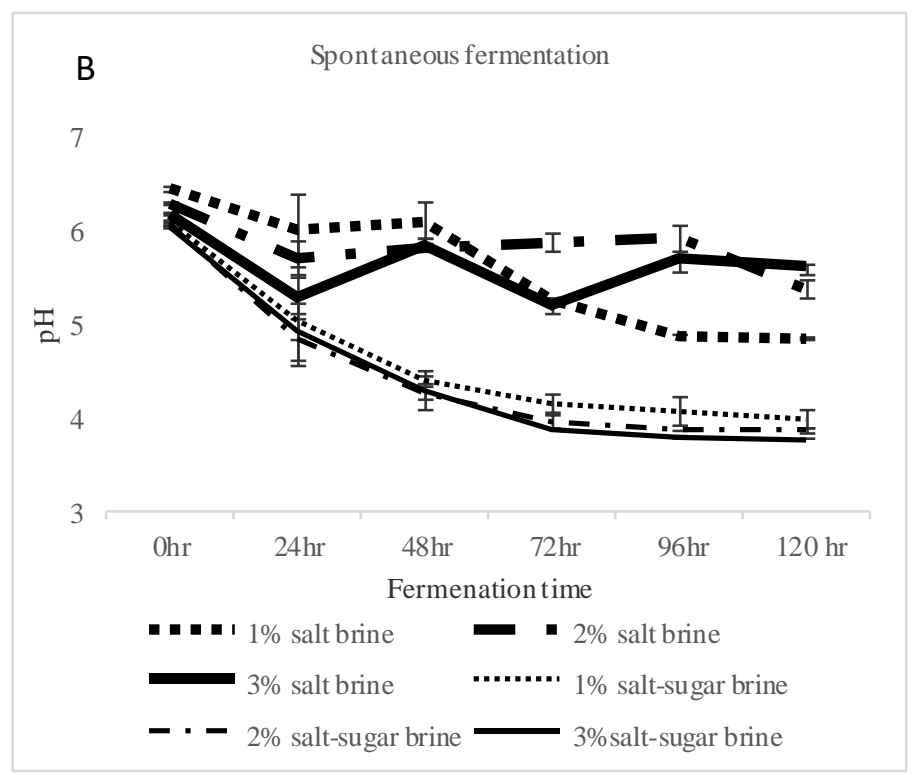

Figure 3 Mean of $\mathrm{pH} \pm \mathrm{SEM}$ from duplicate common bean fermentations (A) inoculated with starter culture Lactobacillus plantarum BFE 5092 and (B) spontaneously fermented in $1 \%, 2 \% \& 3 \%$ salt and salt-sugar brine 
Salt-sugar brine systems were able to significantly $(\mathrm{P}<0.05)$ lower the $\mathrm{pH}$ during common beans fermentation compared to salt brine system after $24 \mathrm{~h}$ of fermentation. Johanningsmeier et al. (2012) established that salt results in slow $\mathrm{pH}$ decline during fermentation. This agrees with the findings of this study. Though inoculated batches had lower $\mathrm{pH}$ compared to the spontaneously fermented ones (Fig.3), the difference was not statistically significant $(\mathrm{P}>0.05)$. These findings are similar with those of Sanchez et al. (2001) who reported that the use of starter culture did not really affect the $\mathrm{pH}$ and acid production in a fermentation system. The concentration of either salt or salt-sugar brine did not have any significant effect $(\mathrm{P}>0.05)$ on $\mathrm{pH}$ of the common beans during fermentation.

Effect of brine solution on the microbial safety in common bean fermentation.

No moulds were detected throughout the fermentation period in both salt and salt-sugar brine systems. Enterobacteria presence in the cooked beans is attributable to the storage and thawing time that could have allowed the proliferation of psychrophilic strains prior to fermentation. The counts in inoculated salt and salt-sugar brine systems (Fig.4) increased significantly
( $\mathrm{P}<0.05$ ) from $10^{4} \mathrm{cfu} / \mathrm{ml}$ and $10^{3} \mathrm{cfu} / \mathrm{ml}$ to $10^{7} \mathrm{cfu} / \mathrm{ml}$ respectively after $24 \mathrm{~h}$ of fermentation. The counts continued to increase to a maximum of between $10^{8}$ and $10^{10} \mathrm{cfu} / \mathrm{ml}$ after $72 \mathrm{~h}$ of fermentation in salt brine system followed by a slight decline by the end of fermentation. In salt-sugar brine systems, the counts began to decline after $48 \mathrm{~h}$ of fermentation and significantly so after $72 \mathrm{~h}$ to $\leq 10^{4}$ $\mathrm{cfu} / \mathrm{ml}$ after $120 \mathrm{~h}$ of fermentation. $1 \%$ salt-sugar brine was able to lower the Enterobacteria to non detectable levels after $120 \mathrm{~h}$ of fermentation. A similar trend was observed in the spontaneously fermented batches (Fig.5). Spontaneous fermentation in salt-sugar brine systems were able to reduce the Enterobacteria to $\leq 10^{4} \mathrm{cfu} / \mathrm{ml}$ after $96 \mathrm{~h}$ of fermentation in comparison to the inoculated batches that were able to do so after $120 \mathrm{~h}$ of fermentation. Though Enterobacteria counts remained high in salt brine system, batches inoculated with Lactobacillus plantarum BFE 5092 was able to restrict their growth albeit after $96 \mathrm{~h}$ of fermentation. Enterobacteria counts increase during fermentation in salt brine is attributable to the inability of the LAB in these systems lower the $\mathrm{pH}$ to below 4.5 (Fig.3). Salt-sugar brine systems were able to lower $\mathrm{pH}$ to below 4.5 hence inhibiting the growth of Enterobacteria. Maina et al. (2004) reported similar findings in fermented milk, Enterobacteria was detectable in samples with $\mathrm{pH} \geq 4.5$ and none was detected in the systems with $\mathrm{pH} \leq 4.5$.

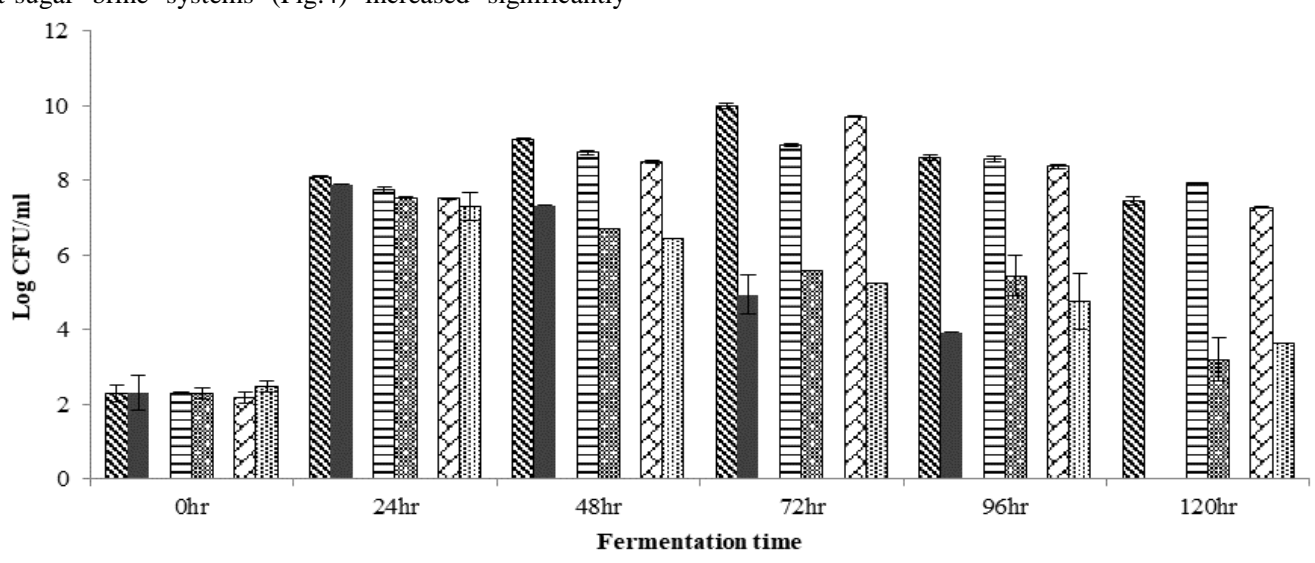

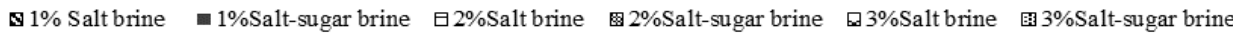

Figure 4 The mean Enterobacteria counts \pm SEM from duplicate common bean fermentations inoculated with starter culture Lactobacillus plantarum BFE 5092 in 1\%, 2\% \&3\% salt,and salt-sugar brine systems

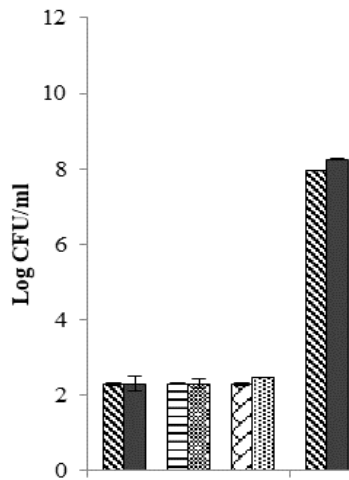

Ohr

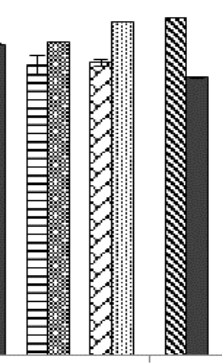

$24 \mathrm{hr}$

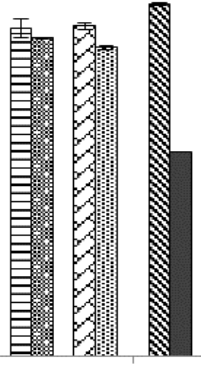

$48 \mathrm{hr}$

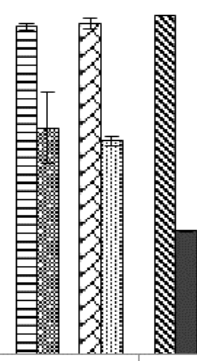

$72 \mathrm{hr}$

Fermentation time

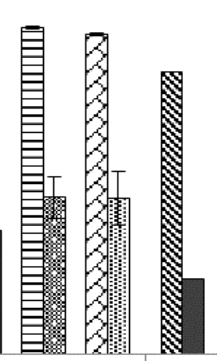

$96 \mathrm{hr}$

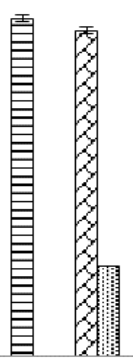

$120 \mathrm{hr}$

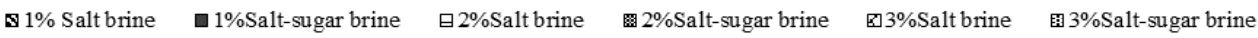

Figure 5 The mean Enterobacteria counts \pm SEM from duplicate spontaneous common bean fermentations in $1 \%$, $2 \% \& 3 \%$ salt and salt-sugar brine

As enterobacteria in salt-sugar brine systems declined, growth of yeast was observed in both the inoculated and spontaneously fermented batches except in $1 \%$ salt-sugar brine (Fig.6). Similar observations were reported by Maina et al. (2004) in fermented milk samples with $\mathrm{pH}$ below 4.5 as is the case with saltsugar brine systems fermentation systems in this study. The yeast count continued to increase with increase in fermentation time. No yeast was detected in salt brine systems a phenomenon that can be attributed to the high $\mathrm{pH}$ in the fermentation and presence of Enterobacteria (Maina et al., 2004).
No statistically significant effect $(\mathrm{P}>0.05)$ was observed as a result of inoculation with Lactobacillus plantarum BFE 5092 (Fig.4) or spontaneously fermenting (Fig.5) whole common beans in regards to inhibition of Enterobacteria and change in the concentration of the brine solutions used. Rather, the inhibition of the Enterobacteria and the growth of yeast in this experiment were largely dependent on the $\mathrm{pH}$ of the fermentation systems. Therefore salt-sugar brine fermentation system was able to inhibit enterobacteria, unlike salt brine systems due to its ability to lower the $\mathrm{pH}$ to below 4.5 . 


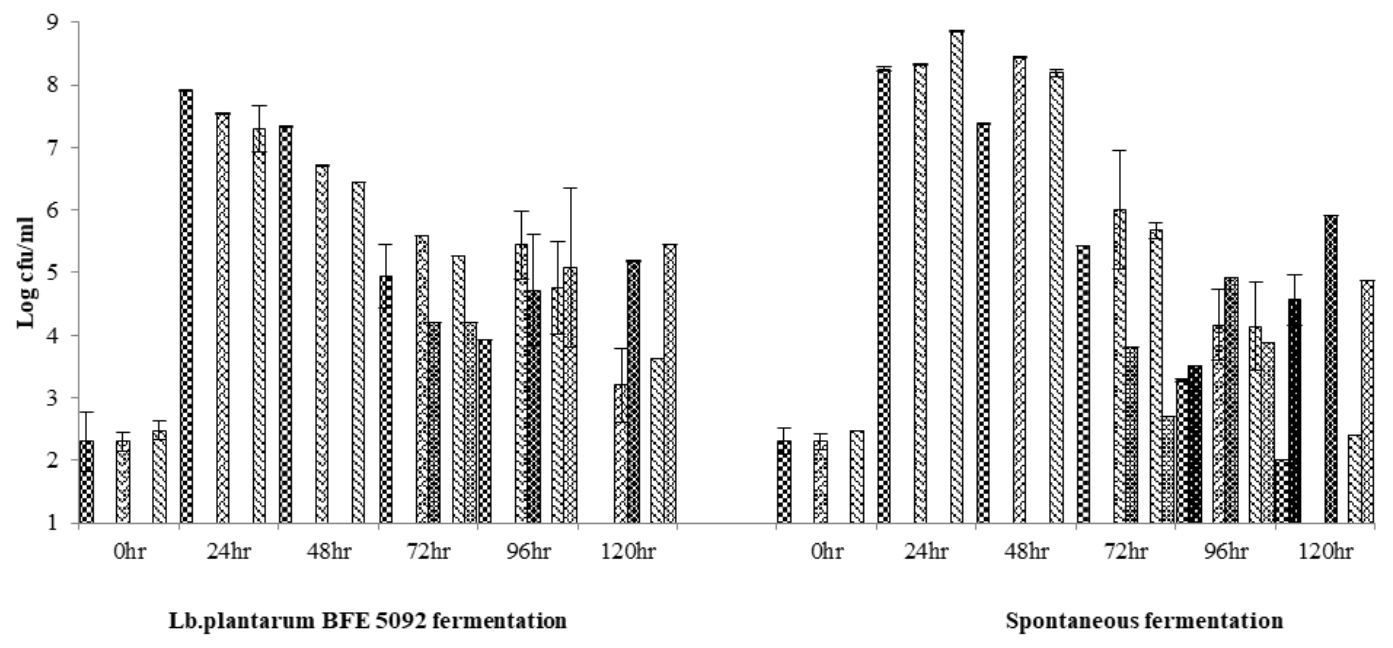

QEnterobacteria $1 \% \mathrm{SSBF}$ Yeast $1 \% \mathrm{SSBF}$ Enterobacteria $2 \% \mathrm{SSBF}$ Yeast $2 \% \mathrm{SSBF}$ \&Enterobacteria $3 \% \mathrm{SSBF}$ Yeast $3 \% \mathrm{SS}$
Figure 6 The mean Enterobacteria and yeast counts \pm SEM from duplicate common bean fermentations inoculated with
starter culture Lactobacillus plantarum BFE 5092 and spontaneous fermentation in $1 \%, 2 \% \& 3 \%$ SSBF (Salt-Sugar Brine Fermentation)

\section{CONCLUSION}

The experiment was set up to develop a protocol for fermenting whole common beans using Lactobacillus plantarum BFE 5092 as a starter culture. Salt and saltsugar brine systems were used at $1 \%, 2 \%$ and $3 \%$ concentration each. It was established that inoculation with Lactobacillus plantarum BFE 5092 had a significant effect on fermentation only when salt brine system were used. Saltsugar brine system promoted a higher and faster growth of LAB in both innoculated and spontaneous fermentation. They also lowered the $\mathrm{pH}$ of the fermentation systems to below 4.5 after $24 \mathrm{~h}$ unlike salt brine system whose $\mathrm{pH}$ remained above 5 throughout the $120 \mathrm{~h}$ fermentation period. Additionally, saltsugar brine systems inhibited the growth of enterobacteria unlike the salt brine systems in which the growth remained above $10^{6} \mathrm{cfu} / \mathrm{ml}$. The decline in enterobacteria counts in salt-sugar brine fermentation favoured the growth of yeast. Solute concentration did not have a significant effect on the growth of $\mathrm{LAB}$, changes in the $\mathrm{pH}$ of the fermentation systems and microbial safety of the products.Therefore, the use of salt-sugar brine systems is effective in the lactic acid fermentation of whole common bean. Further studies should be done on the nutritional impact of the salt and salt-sugar brine fermentation of common bean.

Acknowledgements: Legume Centre for Food and Nutrition Security (LCEFoNS) (VLIR-UOS funded) for funding the project and JKUAT food microbiology laboratory technical staff for support during the research.

\section{REFERENCES}

Agarwal, A. (2016). Journal of Nutritional Disorders \& Duality of Antinutritional Factors in Pulses. Nutritionist and Aromatherapist, SNDT Women's University, Mumbai, India *Corresponding, 6(1), 1-2. https://doi.org/10.4172/2161-0509.1000e124

Anderssen, E. L., Diep, D. B., Nes, I. F., Eijsink, V. G. H., \& Nissen-Meyer, J. (1998). Antagonistic activity of Lactobacillus plantarum C11: Two new twopeptide bacteriocins, plantaricins $\mathrm{EF}$ and $\mathrm{JK}$, and the induction factor plantaricin A. Applied and Environmental Microbiology, 64(6), 2269-2272.

Assohoun, M. C. N., Djeni, T. N., Koussémon-Camara, M., \& Brou, K. (2013). Effect of Fermentation Process on Nutritional Composition and Aflatoxins Concentration of Doklu, a Fermented Maize Based Food. Food and Nutrition Sciences, 4, 1120-1127. https://doi.org/10.4236/fns.2013.411146

Assohoun, M. C. N., Djeni, T. N., Marina., K., \& Brou, K. (2013). Effect of Fermentation Process on Nutritional Composition and Aflatoxins Concentration of Doklu , a Fermented Maize Based Food. Food and Nutrition Sciences, 2013(November), 1120-1127.

Berrios, J. D. J., P, M., Cámara.M, \& Sánchez-mata.M C. (2010). Carbohydrate composition of raw and extruded pulse flours. Food Research International, 43(2), 531-536. https://doi.org/10.1016/j.foodres.2009.09.035

Cho, G. S., Huch, M., Hanak, A., Holzapfel, W. H., \& Franz, C. M. A. P. (2010).
Genetic analysis of the plantaricin EFI locus of Lactobacillus plantarum PCS20 reveals an unusual plantaricin $\mathrm{E}$ gene sequence as a result of mutation. International Journal of Food Microbiology, 141(SUPPL.), S117-S124. https://doi.org/10.1016/j.ijfoodmicro.2010.02.022

El-din, I. M. K. (2010). Characterization of Lactic Acid Bacteria from Egyptian Environment and their Bioactive Products Islam Mohamed Kamal El-Din.

Granito, M., \& Alvarez, G. (2006). Lactic acid fermentation of black beans ( Phaseolus vulgaris ): microbiological and chemical characterization, 1171(November 2005), 1164-1171. https://doi.org/10.1002/jsfa

Johanningsmeier, S. D., Franco, W., Perez-diaz, I., \& Mcfeeters, R. F. (2012). Influence of Sodium Chloride, $\mathrm{pH}$, and Lactic Acid Bacteria on Anaerobic Lactic Acid Utilization during Fermented Cucumber Spoilage, 77(7). https://doi.org/10.1111/j.1750-3841.2012.02780.x

Kinyanjui, P. K., Njoroge, D. M., Makokha, A. O., Christiaens, S., Ndaka, D. S., \& Hendrickx, M. (2015). Hydration properties and texture fingerprints of easyand hard-to-cook bean varieties. Food Science \& Nutrition, 3(1), 39-47. https://doi.org/10.1002/fsn3.188

Legesse, H., Nigussie-Dechassa, R., Setegn, G., \& G, B. (2015). Chemical Quality of Common Beans as Influenced by Genotype and Aluminium Rates Under Two Soil Liming Regimes. African Journal of Food, Agriculture, Nutrition And Development, 15(2), 9872-9891.

Maina, J., Schillinger, U., Museve, P., Mbugua, S. K., \& Holzapfel, W. H. (2004). Isolation , identification and characterisation of the dominant microorganisms of kule naoto : the Maasai traditional fermented milk in Kenya, 94, 269-278. https://doi.org/10.1016/j.ijfoodmicro.2004.01.008

Maina, J., Ulrich, M. Æ., Phillip, S. Æ., Mbugua, S. K., Guigas, Æ. C., Franz, Æ. C., \& Holzapfel, Æ. W. H. (2008). Functional Properties of Lactobacillus plantarum Strains Isolated from Maasai Traditional Fermented Milk Products in Kenya, 315-321. https://doi.org/10.1007/s00284-007-9084-6

Mcphee, K. E., Zemetra, R. S., \& Brown, J. (2002). Genetic Analysis of the Raffinose Family Oligosaccharides in Common Bean, 127(3), 376-382.

Oguntoyinbo, F. A., Cho, G., Brinks, E., Fiedler, G., Kabisch, J., Koberg, S., \& Bockelmann, W. (2016). Draft Genome Sequence of Lactobacillus plantarum BFE 5092 Isolated from Maasai Fermented Milk, 4(3), 2007-2008. https://doi.org/10.1128/genomeA.00481-16.Copyright

Ojokoh, A. O., Daramola, M. K., \& Oluoti, O. J. (2013). Effect of fermentation on nutrient and anti-nutrient composition of breadfruit ( Treculia africana ) and cowpea ( Vigna unguiculata ) blend flours, 8(27), 3566-3570. https://doi.org/10.5897/AJAR12.1944

Onwurafor, E. U., Onweluzo, J. C., \& Ezeoke, A. M. (2014). Effect of Fermentation Methods on Chemical and Microbial Properties of Mung Bean ( Vigna radiata ) Flour. Nigerian Food Journal, 32(1), 89-96. https://doi.org/10.1016/S0189-7241(15)30100-4

Osman, M. A., \& Gassem, M. (2013). Effects of domestic processing on trypsin inhibitor, phytic, acid, tannins and in-vitro Protein Digestibility of three sorghum varieties, 9(5), 1189-1198. 
Pundir, R., \& Jain, P. (2010). Change in microflora of sauerkraut during fermentation and storage. World J. Dairy Food Sci. Retrieved from http://idosi.org/wjdfs/wjdfs5(2)/19.pdf

Reina, L. D., Pérez-Díaz, I. M., Breidt, F., Azcarate-Peril, M. A., Medina, E., \& Butz, N. (2015). Characterization of the microbial diversity in yacon spontaneous fermentation at $20^{\circ} \mathrm{C}$. International Journal of Food Microbiology, 203, 35-40. https://doi.org/10.1016/j.ijfoodmicro.2015.03.007

Sanchez, A., Rejano, L., \& Montano, A. (2001). Utilization at high pH of starter cultures of lactobacilli for Spanish-style green olive fermentation, 115-122.

Saraswathy, N., \& Sadasivam, S. (2010). Degradation of flatulence-causing oligosaccharides in soymilk by $\alpha$-galactosidase - A novel thermotolerant from Penicillium purpurogenum. Indian Journal of Biotechnology, 9(April), 160-165.

Tope, A. K. (2014). Effect of fermentation on nutrient composition and antinutrient contents of ground Lima bean seeds fermented with Aspergillus fumigatus , Rhizopus stolonifer and Saccharomyces cerevisiae Materials and Methods ., 2(7), 1208-1214.

Wafula, E. N., Franz, C. M. A. P., Rohn, S., Huch, M., Mathara, J. M., Trierweiler, B., \& Becker, B. (2015). “ Management of land use systems for enhanced food security : conflicts , controversies and resolutions " Fermentation of African Leafy Vegetables to Lower Post-Harvest Losses , Maintain Quality and Increase Product Safety, 76131. 